\title{
A Reflectance Model for Relatively Clear and Turbid Waters
}

\author{
S. P. Tiwari \\ Dept. of Ocean \\ Engineering \\ Indian Institute of \\ Technology Madras \\ Chennai-600036, India \\ sptiwariiitm@gmail.com
}

\author{
P. Shanmugam \\ Dept. of Ocean \\ Engineering \\ Indian Institute of \\ Technology Madras \\ Chennai-600036, India \\ pshanmugam@iitm.ac.in
}

\author{
Y. H. Ahn \\ Korea Ocean Satellite \\ Center \\ Korea Institute of Ocean \\ Science \& Technology \\ Seoul-425600, Korea \\ yhahn@kiost.ac
}

\author{
J. H. Ryu \\ Korea Ocean Satellite \\ Center \\ Korea Institute of Ocean \\ Science \& Technology \\ Seoul-425600, Korea \\ jhryu@kiost.ac
}

\begin{abstract}
Accurate modeling of spectral remote sensing reflectance $\left(R_{r s}\right)$ is of great interest for ocean colour studies in highly turbid and relatively clear waters. In this work a semianalytical model that simulates the spectral curves of remote sensing reflectance of these waters is developed based on the inherent optical properties (IOPs) and $f$ and $Q$ factors. For accommodating differences in the optical properties of the water and accounting for their directional variations, IOPs and $f$ and $Q$ factors are derived as a function of phytoplankton pigments, suspended sediments and solar zenith angle. Results of this model are compared with in-situ bio-optical data collected at 83 stations encompassing highly turbid/relatively cleared waters of the South Sea of Korea. Measured and modeled remote sensing reflectances agree favorably in both magnitude and spectral shape, with considerably low errors (mean relative error MRE - 0.0327 ; root mean square error RMSE 0.205 , bias $-\mathbf{0 . 0 7 2 7}$ and slope 1.15 and correlation coefficient $R^{2} 0.74$ ). These results suggest that the new model has the ability to reproduce measured reflectance values and has potentially profound implications for remote sensing of complex waters in this region.
\end{abstract}

Keywords-remote sensing reflectance; semianalytical model; optical properties; coastal oceanic waters.

\section{APPENDIX}

\section{SS}

$I O P S$ inherent optical properties

$A O P S \quad$ apparent optical properties

Chl concentration of chlorophyll $\left(\mathrm{mg} \mathrm{m}^{-3}\right)$

$L_{w}\left(\lambda, 0^{+}\right)$water-leaving radiance in the viewing direction $\mathrm{W} \mathrm{m}^{-2} \mathrm{sr}^{-1} \mathrm{~nm}^{-1}$

$R_{r s}(\lambda) \quad$ above-surface remote sensing reflectance $\left(\mathrm{sr}^{-1}\right)$

$R\left(0^{-}\right) \quad$ sub-surface irradiance reflectance $\left(\mathrm{sr}^{-1}\right)$

$f \quad$ anisotropy factor of the light filed in the water

$Q \quad$ bidirectionality factor (a ratio of upward irradiance to upward

radiance under water) dimensionless

$\theta_{\text {sun }} \quad$ zenith solar angle (degree)

$\varpi \quad$ single scattering albedo

$\omega_{b_{b}} \quad$ backscattering albedo

$a(\lambda) \quad$ total absorption coefficient of water $\left(\mathrm{m}^{-1}\right)$

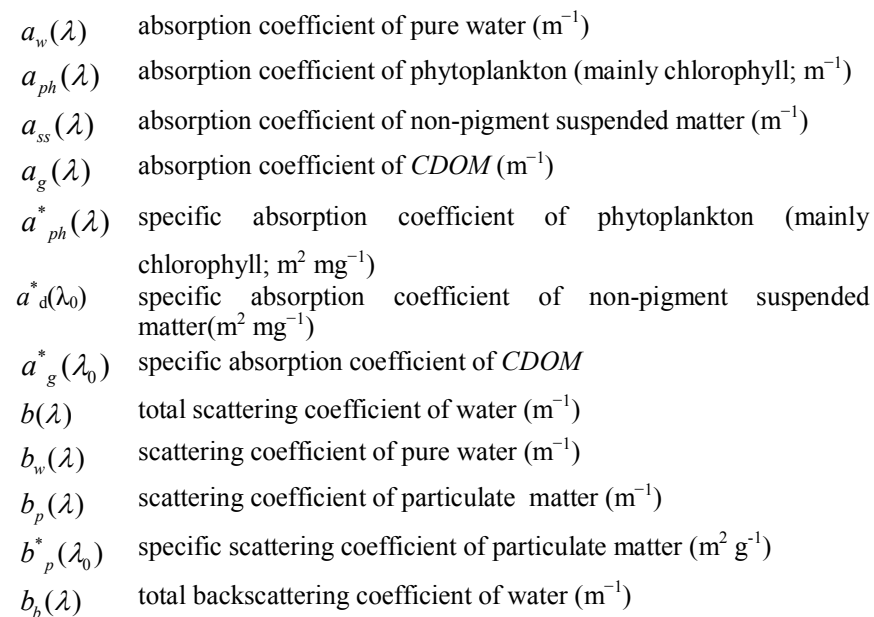

\section{INTRODUCTION}

The intrinsic colour of the ocean can be quantified in terms of spectral remote sensing reflectance, $R_{r s}(\lambda)$, which provides measures of the ratio of upwelling to downwelling light at the water surface. To first-order approximation, the ocean reflectance varies as the ratio of the backscattering coefficient, $b_{b}(\lambda)$, to absorption coefficient, $a(\lambda)$, of seawater [1-4]. Thus, the spectral character of natural light leaving the ocean depends largely on $b_{b}(\lambda) / a(\lambda)$, both are inherent optical properties $(I O P S)$ that depend on the types and concentrations of various constituents present in the water. Properties that are directly derived from the light field (e.g., $R_{r s}$ or $R_{r s}$ both spectral-dependent terms) are called the apparent optical properties $(A O P S)$, thus when there is a change in light field that enters the ocean, it does not affect the IOPs. In order to deduce from these ocean colour properties the substances present in water and their concentrations, it is imperative to understand how different constituents of water contribute to absorption $(\alpha)$ and backscattering $\left(b_{b}\right)$ of light. 
Optical properties of water vary for two primary reasons: variations in the concentrations of water constituents and variations in the materials themselves, e.g., variations in the size and refractive index of particles. An ocean colour model parameterized for a set of optically active constituents should be able to describe optical variability due to varying concentrations of those constituents. Such a model could then be inverted successfully to retrieve the constituents' concentrations and IOPS [2]. Presently, empirical algorithms often focus only on retrieving a single constituent concentration, whereas semi-analytical algorithms are capable of retrieving three or more constituents simultaneously [5]. For semi-analytical algorithms, an inversion technique is usually applied to a parameterized ocean colour model whose parameters are determined from in situ bio-optical measurements [6-13]. Precise radiative transfer calculations [1, 14] have provided a solid physical and analytical basis for quantitatively interpreting a measured ocean colour spectrum as a function of the IOPs (i.e., absorption and backscattering coefficients).

The forward technique for remote sensing is used to predict the spectral intensity of the light based on a quantitative description of all the absorption, scattering and reflection characteristics of the optical components in the ocean. The simulation of the surface $R_{r s}(\lambda)$ as a function of both absorption and backscattering usually represents the reflected ocean signals from various in-water constituents. Thus, the prediction of the availability and propagation of underwater lights from knowledge of its particulate and dissolved concentrations of water constituents is referred to as the forward modeling [15]. It is generally estimated based on the particle size distribution, refractive index of seawater, and optical bidirectional quantities $Q$ and $f$ that mainly depend on the geometric structure of the light field. Of these, the values of $f$ factor vary $[14,16]$ with the illumination conditions at the surface (essentially with the Sun position for clear skies). Given an incident radiant field, $f$ also depends on the IOPS of the water body and thus on the Chl concentration and wavelength [17]. For remote sensing applications, the $f / Q$ factor is described as a function of Chl for Case 1 waters [18, 19]. However, in Case 2 waters, by definition, the IOPs are not determined by $C h l$ alone because of the presence of other particles that do not co-vary with $C h l$ and therefore a Case 1 water model for bidirectional effects is clearly not applicable.

The objective of this study is to develop a semi-analytical ocean colour model for coastal oceanic waters. The new model incorporates the empirical relationships for IOPs, analytical expressions for total backscattering coefficients and the values of bidirectional parameters. The empirical relationships are developed based on a large in-situ data of IOPs and describe the variability of the four major components, such as backscattering $\left(b_{b}(\lambda)\right)$ by all particles and the absorption by pure seawater $\left(a_{w}(\lambda)\right)$, phytoplankton $\left(a_{p h}(\lambda)\right)$, gelbstoff $\left(a_{g}(\lambda)\right)$ and sediment (detritus) particles $\left(a_{d}(\lambda)\right)$. This paper also includes the bidirectional reflectance parameter term $(f / Q)$, particularly in view of improving the present ocean colour model.

\section{FORMULATION OF REFLECTANCE MODEL}

The present semi-analytical model includes the radiative transfer expressions and empirical relationships derived from in-situ data sets. In the following sections, the theoretical basis of this model and procedures for deriving its input parameters are presented. The derivation of individual terms in the radiative transfer equations is described and usefulness of the model is discussed.

Ocean colour is essentially the spectrum of light leaving the ocean, normalized to the incident light on ocean surface, carrying with it information on IOPS (total backscattering $b_{b}(\lambda)$ and total absorption $a(\lambda)$ of the water. Thus, spectral $R_{r s}(\lambda)$ is related to backscattering, which redirects downwelling photons to travel upward and eventually leave the water surface, and absorption, which converts photons to heat or chemical energy. As upward traveling photons exit the water, they interact with air-water interface by refraction and internal reflection [20]. Radiative transfer studies have shown that spectral $R_{r s}(\lambda)$ at any wavelength $\lambda$ can be modeled through the approximation $[21-23 ; 18]$ :

$$
\begin{aligned}
& R_{r s}(\lambda)=\frac{t^{2}}{n^{2}} \times R\left(\lambda, 0^{-}\right)=\frac{f(\lambda) t^{2}}{Q(\lambda) n^{2}}\left[\frac{b_{b}(\lambda)}{a(\lambda)+b_{b}(\lambda)}\right] \\
& =0.54 \frac{f(\lambda)}{Q(\lambda)}\left[\frac{b_{b}(\lambda)}{a(\lambda)+b_{b}(\lambda)}\right]
\end{aligned}
$$

Both $R_{r s}(\lambda)$ and $R\left(\lambda, 0^{-}\right)$are apparent optical properties (AOPS) as they are dependent upon the directional structure of the radiance distribution as well as the optical characteristics of the medium [24]. In theory, the bidirectional parameter of remote sensing reflectance of optical field $Q$ ranges from 0.3 to 6.5 , but is generally expected to be 3 [19], $n$ is the refractive index of seawater; Austin [25] proposed the factor 0.54 for correlating radiance just above the surface to radiance just beneath the surface $\left(t^{2} / n^{2}=0.54\right.$ is transmissibility of air-water interface), $f$ is a constant of proportionality [19] and a function of solar zenith angle. However, a wide range of values of $f$ is commonly found in the literature, from 0.33 [1] to 0.089 [26]. As reported earlier, $f / Q\left(f / Q=0.095\right.$ for $\theta_{\text {sun }}$ $=>20^{\circ}$ ) is independent of the solar zenith angle changes [21, 27].

Especially, both $f$ and $Q$ are the key parameters which connect the remote sensing reflectance above the water to the $I O P$ parameters (e.g., absorption and scattering). According to the recent studies, the values of bidirectional reflectance parameters $Q$ and $f$ have to be predetermined or are 
considered constant for simulation of $R_{r s}(\lambda)$. However, these optical parameters can be affected by many factors, including the viewing geometry of the sensor, the roughness of water surface, the bidirectional reflectance of water and the atmospheric condition, and are often different at different water locations and times [26]. Estimating the values of $Q$ and $f$ by inappropriate optical models or ignoring their variations will therefore introduce large errors in retrieved water qualities. This problem could be solved by calculating and incorporating the effects of bidirectional quantities ( $f$ and $Q$ ) on optical properties of marine waters. In many previous studies, the values of $f$ and $Q$ are set to be constant, for instance $f$ equals 0.33 [28] and the $Q$ parameter is universally equal to 3.14 [29, 30]. In other studies, the values of $f$ and $Q$ are calculated from optical models, which take the mean cosine $\left(\mu_{0}\right)$ or $\theta_{\text {sun }}$ as inputs $[2,27]$. It is more appropriate to calculate the values of $f$ and $Q$ from optical models than to set them to be constants. Thus, the sun angle is used for calculating the $f$ value according to Morel and Gentili [27] in (2).

Their relationship for deriving $f$ values can be expressed as a function of the ratio of the molecular backscattering to total backscattering $\eta_{b}\left(=b_{b w}(\lambda) / b_{b}(\lambda)\right)$, single scattering albedo $\varpi$ and solar zenith angle $\cos \left(\theta_{\text {sun }}\right)$ as follows:

$$
\begin{aligned}
& f(\lambda)=0.5575-0.1067 \times \eta_{b}+0.1045 \varpi-0.0231 \times \eta_{b}{ }^{2}+ \\
& 0.0167 \times \varpi^{2}-0.2189 \times \eta_{b} \times \varpi+ \\
& \left(-0.2796+0.1875 \times \eta_{b}-0.0401 \times \varpi-0.0111 \times \varpi^{2}+\right. \\
& \left.0.0795 \times \eta_{b} \times \varpi\right) \cos \left(\theta_{\text {sun }}\right)
\end{aligned}
$$

where $\varpi=b /(b+a)=b / c$ is the single scattering albedo in which $a$ and $c$ are the absorption and attenuation coefficients respectively. In the above equation, the backscattering albedo $\left(\omega_{b_{b}}(\lambda)\right)$ is used as an alternative of the single scattering albedo. $\theta_{\text {sun }}$ is the sun zenith angle. Equation (2) takes into consideration the fact that $f$ depends not only on the geometric structure of the light field, expressed by the parameter $\theta_{\text {sun }}$, but also on the absorption and scattering properties of the water.

The spectral behavior of the bidirectional factor $Q$, which is the ratio of the upwelling irradiance to upwelling radiance, $E_{u}(\lambda) / L_{u}(\lambda)$, is determined by the expression: $Q=R(\lambda) / R_{r s}-(\lambda)$, where $R(\lambda)$ is the irradiance reflectance and $R_{r s}{ }^{-}(\lambda)$ is the remote sensing reflectance below the surface. $R_{r s}{ }^{-}(\lambda)$ can be calculated using the following relationship [31]:

$$
R_{r s}^{-}(\lambda)=f_{r s} \times \omega_{b}(\lambda)
$$

The factor $b_{b}(\lambda) /\left(a(\lambda)+b_{b}(\lambda)\right)$ is an angle-independent factor that determines the water reflectance, which represents the probability of backscattering per extinction event when the quasi-single-scattering approximation is valid; i.e., when the forward scattered photons are considered not to be removed from the incident beam [32]. Thus, the backscattering albedo is described as follow:

$$
\omega_{b}(\lambda)=b_{b}(\lambda) /\left(a(\lambda)+b_{b}(\lambda)\right)
$$

Further simplification of (3) for derivation of remote sensing reflectance below the surface as a function of the total absorption and backscattering leads to [33]:

$$
R_{r s}-(\lambda)=f_{r s} \times \frac{b_{b}(\lambda)}{a(\lambda)+b_{b}(\lambda)}
$$

where,

$$
\begin{aligned}
& f_{r s}(\lambda)=0.0512 \times\left(1+4.6659 \times \omega_{b}-7.8387 \times \omega_{b}{ }^{2}+\ldots\right. \\
& \left.\ldots+5.4571 \times \omega_{b}{ }^{3}\right) \times\left(1+\frac{0.4021}{\cos \theta_{v}}\right) \times\left(1+\frac{0.1098}{\cos \theta_{\text {sun }}}\right)
\end{aligned}
$$

The determination of the remote sensing reflectance from the irradiance reflectance is possible using the $Q$ factor, $R_{r s}{ }^{-}(\lambda)=R(\lambda) / Q$. The $Q$ factor is determined by the angular distribution of the underwater light field. The angular distribution of light is in turn controlled significantly by the $I O P S$ and their concentrations; therefore, a parameterization of $Q=R(\lambda) / R_{r s}{ }^{-}(\lambda)$. Moreover, the $Q$ factor is derived as a function of solar zenith angle in-water and viewing angle inwater.

$$
R(\lambda)=f \times \frac{b_{b}(\lambda)}{a(\lambda)+b_{b}(\lambda)}
$$

$f$ factor, as given by (6), is used to derive the irradiance reflectance values. $\theta_{\text {sun }}$, and $\theta_{v}$ in (5) are the sun zenith angle (generally it is considered $30^{\circ}$ ) and viewing angle (it is considered $0^{\circ}$ ) respectively.

\section{A. Parameterization of the reflectance model}

\section{1) Absorption terms}

The total absorption can be partitioned into the cumulative sum of individual contributions by optically significant constituents of seawater such as water molecules $a_{w}$, phytoplankton $a_{p h}$, coloured dissolved organic matter $a_{g}$, and suspended sediment $a_{s s}$ :

$$
a_{t}(\lambda)=a_{w}(\lambda)+a_{p h}(\lambda)+a_{g}(\lambda)+a_{s s}(\lambda)
$$


All water constituents are treated as variables and parameterized as a function of $C h l$ and $S S$ concentrations. The above-four components can be further expanded to give $a_{t}(\lambda)$ :

$$
\begin{aligned}
& a_{t}(\lambda)=a_{w}(\lambda)+\left[a_{0}(\lambda)+a_{1}(\lambda) \times \ln (C h l)\right] \times a_{p h}(440)+ \\
& a_{g}(443) \exp \left[-S_{g}(\lambda-443)\right]+a_{s s}(443) \exp \left[-S_{s s}(\lambda-443)\right]
\end{aligned}
$$

where $S_{g}$ and $S_{s s}$ are the spectral slopes of the absorption coefficients of $C D O M$ and $S S$ respectively.

\section{2) Absorption coefficient of water $\left(a_{w}\right)$}

The absorption coefficient of water varies weakly in the near-UV (e.g., $280 \mathrm{~nm}$ ), blue (e.g., $443 \mathrm{~nm}$ ), and green (e.g., $530 \mathrm{~nm}$ ) regions of the spectrum, but increases gradually as the wavelength rises above $570 \mathrm{~nm}$ and becomes significant in the red region (Figure 1). The $a_{w}$ is assumed constant and equal to the reported values for pure water [34]. For visible wavelengths, $a_{w}$ does not change much between the fresh and salt waters [35]. However, due to the dissolved ions in the sea waters $a_{w}$ can change markedly for wavelengths in the UV range [35].

\section{3) Phytoplankton absorption}

The phytoplankton absorption $a_{p h}(\lambda)$ is usually represented as

$a_{p h}(\lambda)=a_{p h}^{*}(\lambda) \times[C h l]$

where $[\mathrm{Chl}]$ is the chlorophyll concentration and $a_{p h}{ }^{*}(\lambda)$ $\left(\mathrm{m}^{2} \mathrm{mg} \mathrm{Chl}{ }^{-1}\right)$ is the $C h l$-specific absorption coefficient of phytoplankton [36, 37]. Changes in cell size and in the composition and degree of packaging of pigments could influence $a_{p h}^{*}(\lambda)$ values $[36,37]$. Thus, $a_{p h}^{*}(\lambda)$ is not constant, but parameterized as a function of $C h l$ [38]:

$$
a_{p h}^{*}(\lambda)=A(\lambda) \times[C h l]^{-B(\lambda)}
$$

where $A(\lambda)$ and $B(\lambda)$ values are wavelength-dependent and measured over the wavelengths from 400-700 nm. This model is mainly applicable in clear waters. Alternatively, Lee in [39] derived $a_{p h}(\lambda)$ empirically as follows:

$$
a_{p h}(\lambda)=\left[a_{0}(\lambda)+a_{1}(\lambda) \times \ln (C h l)\right] \times a_{p h}(440)
$$

where $a_{0}$ and $a_{1}$ are the empirical coefficients from [40], which are then linearly interpolated from 700 to $720 \mathrm{~nm}$ at an equal interval of $2 \mathrm{~nm}$. In the above equation, $a_{p h}(440)$ is estimated as a function of $\mathrm{Chl}$ using (Figure 2a):

$$
a_{p h}(440)=0.0541 \times(C h l)^{0.7491} ; R^{2}=0.8555
$$

This model (11 and 12) reproduces the spectral shapes of the $a_{p h}(\lambda)$ curves with peaks around $440 \mathrm{~nm}$ and $675 \mathrm{~nm}$.

\section{4) CDOM and SS absorption coefficients}

$C D O M$ and $S S$ are the important components of the ocean optical signal for the satellite-based measurements of ocean colour and can interfere in global and regional estimates of primary production [41-43]. It is therefore highly desirable to retrieve the absorption coefficients of $C D O M$ and $S S$ in coastal waters. Since the terms $a_{s s}$ and $a_{g}$ have similar spectral shapes decreasing exponentially with increasing wavelength, they can both be fit to a curve of the form

$$
a_{x}(\lambda)=a_{x}\left(\lambda_{r}\right) e^{-S(\lambda-443)}
$$

The absorption coefficients of $C D O M$ and $S S$ are estimated at two wavelengths (i.e., $a_{x}(412)$ and $\left.a_{x}(443)\right)$ in order to derive slopes of their absorption curves. In this equation, the subscript $x$ refers to either the CDOM absorption or the $S S$ absorption, $S$ is the spectral slope coefficient $\left(\mathrm{nm}^{-1}\right)$ of exponential that determines the shape of the absorption curve, $a_{x}\left(\lambda_{r}\right)$ is the absorption coefficient at a reference wavelength. The slope is used as a proxy for $C D O M / S S$ composition, and is often empirically determined. Earlier studies have reported the average value of the spectral slope $\left(S_{s s}\right)$ for detritus to vary from 0.0058 to $0.011 \mathrm{~nm}^{-1}$ and $\left(S_{g}\right)$ for dissolved materials to vary from 0.014 and $0.015 \mathrm{~nm}^{-1}$ in typical marine environments [44]. The mean spectral slope $\left(S_{g}\right)$ of the overall retrieval determined here is $0.015 \mathrm{~nm}^{-1}$.

a) Empirical relationships for deriving $a_{g}(412)$ and $a_{g}(443)$ and $S_{g}$ coefficients

To estimate the absorption coefficient of $C D O M$ in the visible domain, relationships between the log-transformed $a_{g}$ at 412 and $443 \mathrm{~nm}$ and log-transformed $C h l$ were established using in-situ bio-optical data sets (Figure 3). A goodness of fit was found between $a_{g}$ at 412 and $443 \mathrm{~nm}$ and $C h l$ concentrations, with correlation coefficient $\left(R^{2}\right) 0.63$ for $C h l$ versus $a_{g}(412)$ and 0.46 for $C h l$ versus $a_{g}(443)$. Statistical regression analyses demonstrated the best-fit power functions as described below:

$$
\begin{aligned}
& a_{g}(412)=0.189 \times[C h l]^{0.3448} ; R^{2}=0.63 \\
& a_{g}(443)=0.153 \times[C h l]^{0.3269} ; R^{2}=0.46
\end{aligned}
$$


where $a_{g}(412)$ and $a_{g}(443)$ represent the absorption coefficients of $C D O M$ at 412 and $443 \mathrm{~nm}$, and the values $0.189,0.3448,0.1525$, and 0.3969 are the regression coefficients. The value of $S_{g}$ was derived based on a power fit of the absorption spectra to an exponential function over the wavelength range from 400 to $720 \mathrm{~nm}$ :

$$
S_{g}=\frac{1}{\left(\lambda_{r}-\lambda\right)} \log _{10}\left(\frac{a_{g}(412)}{a_{g}(443)}\right)
$$

The derived slope values are consistent with those of the measured values in the study region
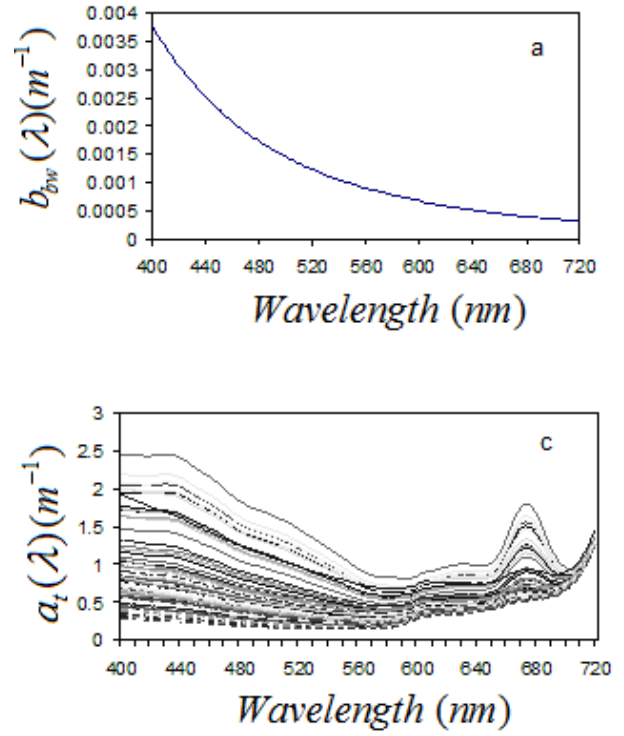
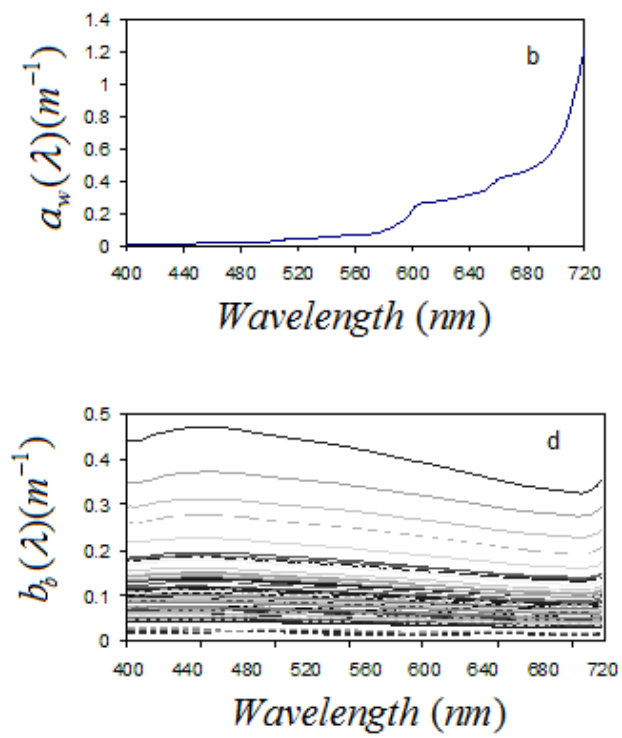

Fig. 1. Absorption and backscattering coefficients of pure seawater (a and b) and variability of the total absorption and backscattering spectra of coastal oceanic waters (c and d).
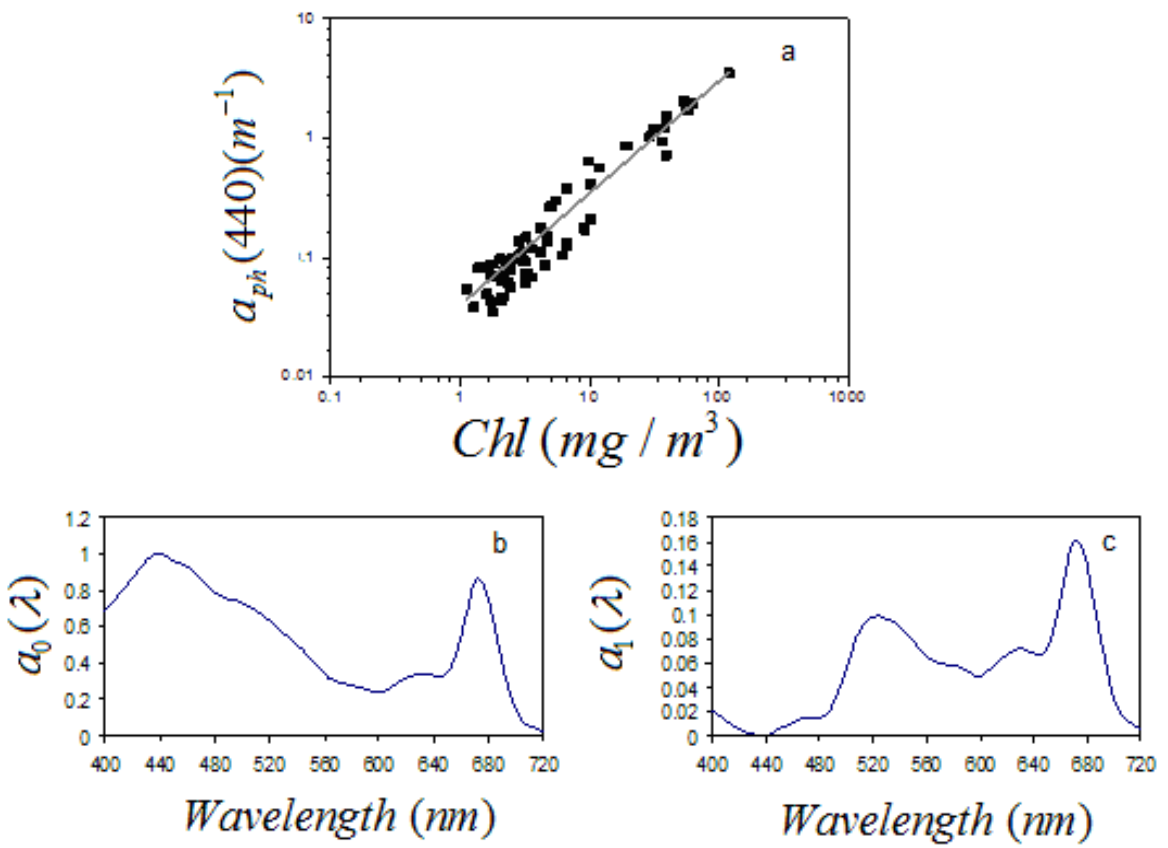

Fig. 2. (a) The empirical relationships between the $a_{p h}(440)$ and $C h l$ concentrations from in-situ data sets ( $\left.\mathrm{N}=83\right)$. Panels $\left(\mathrm{b}\right.$ and c) are the $a_{0}$ and $a_{1}$ coefficients. 
b) Empirical relationships for deriving $a_{s s}(412)$ and $a_{s s}(443)$ and $S_{s s}$ coefficient

The absorption by suspended sediment ( $S S$ ) is treated separately as it has a significant influence on the remote sensing reflectance spectra. Similar to the absorption coefficient of CDOM $a_{s s}$ values were derived at two wavelengths (412 and $443 \mathrm{~nm}$ ) at which high absorption occurs. To estimate the absorption coefficient of $S S$ in the visible domain, relationships between the log-transformed $a_{s s}$ at 412 and $443 \mathrm{~nm}$ and log-transformed [SS] concentrations were established using in-situ bio-optical data sets (Figure 4). The expressions of $a_{s s}$ at 412 and $443 \mathrm{~nm}$ are given by:

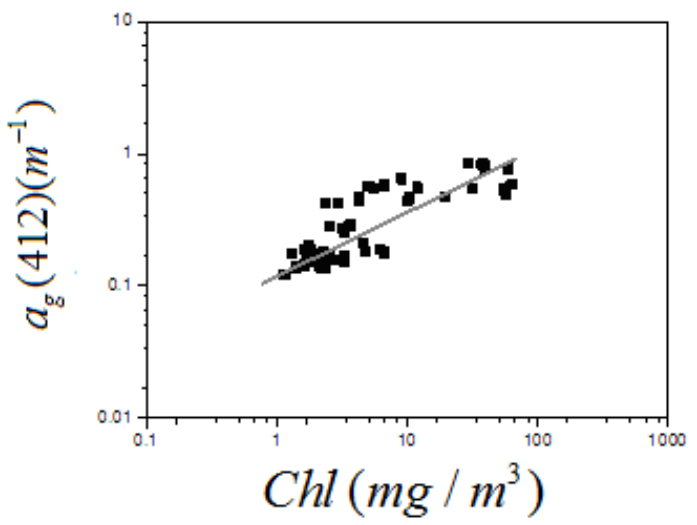

Fig. 3. The empirical relationships between the $a_{g}(412), a_{g}(443)$ and $C h l$ concentrations from in-situ data sets $(\mathrm{N}=83)$.

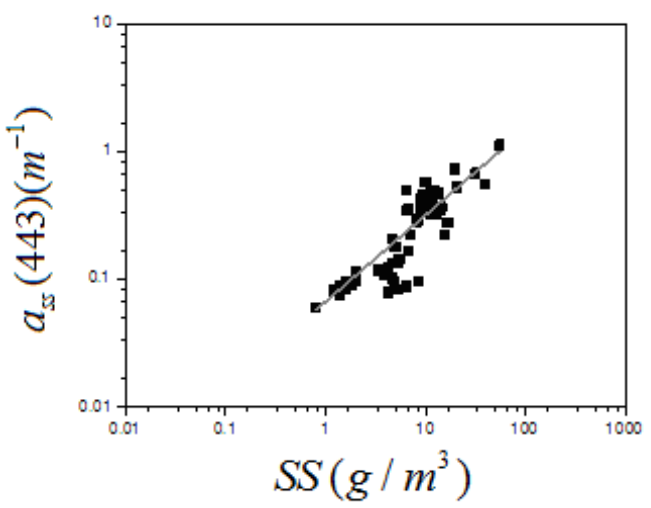

Fig. 4. The empirical relationships between the $a_{s s}(412), a_{s s}(443)$ and $S S$ concentrations from in-situ data sets $(\mathrm{N}=83)$.

\section{B. Backscattering term $\left(b_{b}\right)$}

In bio-optical modeling for remote sensing of chlorophyll in Case 1 waters, analytical approximations of the spectral

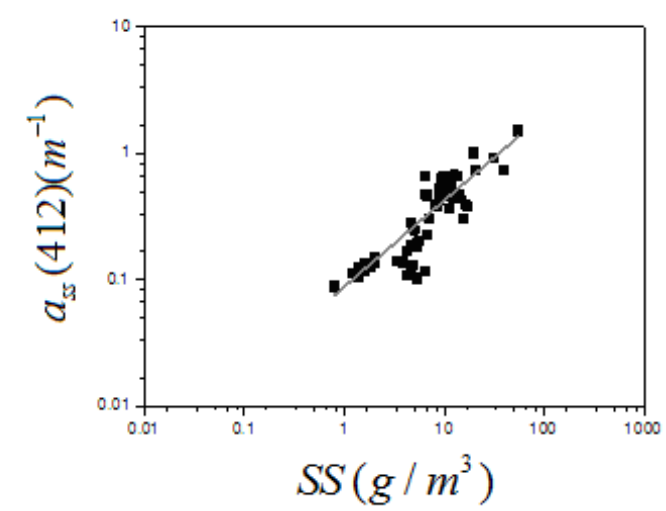

$a_{S S}(412)=0.089 \times[S S]^{0.681} ; \quad R^{2}=0.70$

$a_{s s}(443)=0.067 \times[S S]^{0.5551} ; \quad R^{2}=0.67$

where $a_{s s}(412)$ and $a_{s s}(443)$ represent the absorption coefficients of $S S$ at 412 and $443 \mathrm{~nm}$, and the values 0.0885 , $0.681,0.067$, and 0.551 are the regression coefficients. The value of the spectral slope parameter $\left(S_{s s}\right)$ was derived for the wavelengths 400-720 $\mathrm{nm}$ using:

$$
S_{s s}=\frac{1}{\left(\lambda_{r}-\lambda\right)} \log _{10}\left(\frac{a_{s s}(412)}{a_{s s}(443)}\right)
$$

The derived slope values are comparable with those of the measured values in the study region.

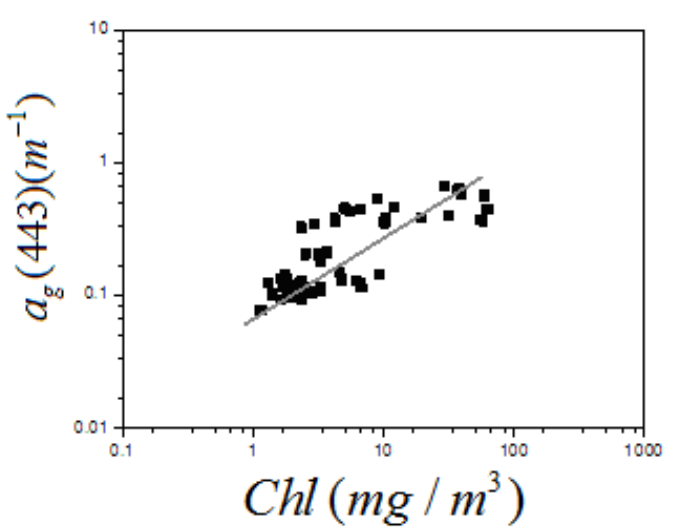

reflectance from the pigment content of water require establishing the relationship between $b_{b}$ and chlorophyll [44, 45]. While the dependency of $b_{p}$ on chlorophyll has been 
empirically determined in several studies (recently by [46]), $b_{b}$ is usually derived from $b_{b p}$, where $b_{b p}$ is modeled semianalytically as a function of chlorophyll $[44,45]$. The $b_{b}(\lambda)$ is partitioned into a constant equal to the reported values for backscatter by pure seawater, $b_{b w}(\lambda)$ [47] and contributions by the particle fraction, $b_{b p}(C h l, \lambda)$ and $b_{b s s}(S S, \lambda)$.

$b_{b}(\lambda)=b_{b w}(\lambda)+b_{b p}(C h l, \lambda)+b_{b s s}(S S, \lambda)$

Since no $b_{b p}(C h l, \lambda)$ and $b_{b s s}(S S, \lambda)$ measurements were made for this study, $b_{b p}(C h l, \lambda)$ and $b_{b s s}(S S, \lambda)$ are derived by considering the typical variations of $b_{b p}{ }_{b p}(550), b_{b s s}{ }^{*}(\lambda)$ and backscattering slope $(Y)$ by particulate matter. Further, the $b_{b}(\lambda)$ can be decomposed as follows:

$$
\begin{aligned}
& b_{b}(\lambda)=(1 / 2) \times b_{w}(\lambda)+0.002+\ldots \\
& \ldots+0.02\left[0.5-0.25 \times \log _{10}[C h l] \times \frac{550}{\lambda}\right] \times \ldots \\
& \ldots \times\left[0.3 \times C^{0.62}-b_{w}(550)\right]+[S S] \times b_{b s s}^{*}(\lambda)
\end{aligned}
$$

For Case 1 water, the individual scattering and absorption can be modeled through empirical formula with only one input variable: concentration of Chl. The derivation of the backscattering coefficient $b_{b}(\lambda)$ starts with the use of an empirical expression [48], which relates the particle scattering coefficient $b_{b p}$ at $550 \mathrm{~nm}$ to [ $\mathrm{Chl}$ ], as follows:

$$
b_{p}(550)=0.3 \times[C h l]^{0.62}
$$

This relationship was indeed established for the total scattering coefficient $b_{p}(550)$ so that $b_{w}(550)$ must be subtracted to obtain $b_{p}(550)$. A more accurate form of (21) should read

$$
b_{p}(550)=0.3 \times[C h l]^{0.62}-b_{w}(550)
$$

Even in the clearest waters, for example, when [ $\mathrm{Chl}] \sim$ $0.02 \mathrm{mg} \mathrm{m}^{-3}$, the molecular scattering represents about $7 \%$ (at $550 \mathrm{~nm}$ ) of the total scattering coefficient; therefore this contribution is negligible considering the uncertainty attached to the above statistical relationship. The particle backscattering coefficient $b_{b p}(\lambda)$ is then obtained from [44] through the expression:

$$
\begin{aligned}
& b_{b p}(C h l, \lambda)=[0.002+0.02(0.5-0.25 \times \ldots \\
& \left.\ldots \times \log _{10}(C h l) \times \frac{550}{\lambda}\right] \times\left[0.3 \times C^{0.62}-b_{w}(550)\right]
\end{aligned}
$$

Note that the wavelength dependency $\lambda^{-1}$ only applies to this part (within the brackets) of the backscattering efficiency (the embrace), which varies with $[C h l]$. Then $b_{b p}(C h l, \lambda)$ is added to $(1 / 2) b_{w}(\lambda)$ to obtain the total backscattering coefficient as follows:

$$
b_{b}(\lambda)=(1 / 2) \times b_{w}(\lambda)+b_{b p}(C h l, \lambda)+b_{b s s}(S S, \lambda)
$$

Conversely to what happens for the total scattering coefficient, the molecular contribution is often important in forming the backscattering coefficient $b_{b}(\lambda)$; in effect, it becomes the dominant term at low chlorophyll concentration. The $b_{b p}(C h l, \lambda)$ is parameterized at a reference wavelength of $550 \mathrm{~nm}$, and the $b_{b w}(\lambda)$ is estimated using a backscattering ratio of 0.5 and the $b_{w}(\lambda)$ of [44] as tabulated in [47].

Backscattering by suspended sediments is derived from the following expression given as below:

$$
b_{b s s}(S S, \lambda)=S S \times b_{b s s}^{*}(\lambda)
$$

where the values of specific backscattering by suspended sediments are taken from [48].

\section{DATA SETS}

In-situ bio-optical data sets collected from a wide range of coastal waters $\left(33.5^{\circ} \mathrm{N} \sim 35.5^{\circ} \mathrm{N} ; 125.5^{\circ} \mathrm{E} \sim 130^{\circ} \mathrm{E}\right)$ around the South Sea of Korea from 2001-2005 have been used to test the performance of the present model. The data sets include the remote sensing reflectance $R_{r s}(\lambda)$, chlorophyll ( $C h l$ ) and suspended sediment ( $S S$ ) concentrations, and absorption by phytoplankton $\left(a_{p h}\right)$, coloured dissolved organic matter $\left(a_{g}\right)$ and suspended sediment matter $\left(a_{s s}\right)$ (more details in [49-51]). After a careful examination, 83 in-water profiles of Chl SS, $a_{s s}, a_{p h}$ and $a_{g}$ and $R_{r s}(\lambda)$ were selected representing highly turbid, relatively cleared and relatively clear waters.

\section{RESUlTS AND DISCUSSIONS}

A. Comparison of the derived absorption spectra $\left(a_{s s}, a_{p h}\right.$ and $a_{g}$ ) with in-situ data

Absorption coefficients of non-algal particles $\left(a_{s s}\right)$ phytoplankton $\left(a_{p h}\right)$ and coloured dissolved organic matter $\left(a_{g}\right)$ derived from the respective models are compared with in-situ data collected at all 83 stations (Figure 5). 

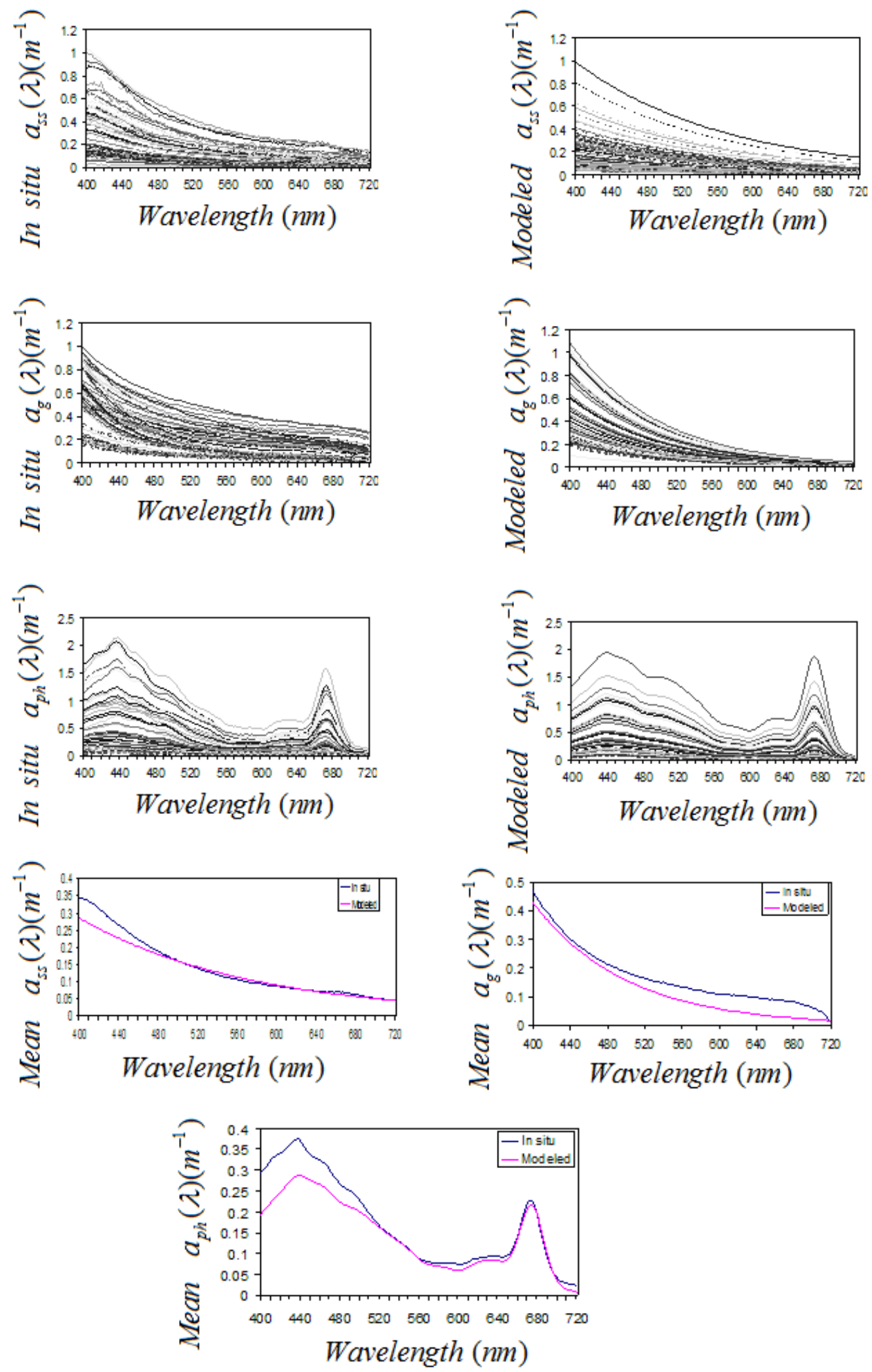

Fig. 5. Comparison of the absorption spectral of $a_{s s}, a_{g}$, and $a_{p h}$ derived from the respective models with those measured from the water samples collected in turbid/relatively clear waters of the South Sea of Korea. Their mean absorption spectra are shown in the bottom panels. 
The fitted spectral values of these numerical coefficients, which are used as inputs to the reflectance model, indicate small differences in the general variability, magnitude and spectral shape of both dissolved and particulate absorptions in turbid and relatively clear waters. $C D O M$ and $S S$ absorption coefficients are strong in the blue (e.g. 412 and 443 $\mathrm{nm}$ ) domain and exponentially decrease towards the longer wavelengths. Looking at their mean absorption curves from the models reveals slightly lower $a_{s s}$ values at $412-443 \mathrm{~nm}$ and lower $a_{g}$ values in the longer wavelengths. Higher values of $a_{g}$ from the in-situ data may result from a contribution of small particles that pass through a pore size of the filter paper $(<0.45$ $\mu \mathrm{m})$. This suggests that $a_{g}$ values derived from the model reduced contributions to absorption by smaller particles. In contrast, absorption coefficients of phytoplankton derived from the model are tightly consistent with measured spectra in the green and red domains, but becoming smaller toward shorter wavelengths. The differences could be related to variability in absorption per unit chlorophyll resulting from pigment packaging effects [52]. As already reported, this spectrum typically has two peaks, one around $443 \mathrm{~nm}$ and another around $670 \mathrm{~nm}$; there is relatively lower absorption between 550 and $650 \mathrm{~nm}$ [50]. These peaks are due to the presence of $C h l$ and the width of the peaks around 440 and $675 \mathrm{~nm}$ varies from sample to sample, due to the change in accessory pigments present and the package effect [52].

\section{B. Comparison of the derived remote sensing reflectance spectra with in-situ spectra}

A set of 83 reflectance spectra were generated using the new model for varying concentrations of $C h l, S S$ and CDOM contents in coastal waters of the South Sea of Korea. To illustrate differences (in terms of spectral shape and magnitude), simulated spectra of $R_{r s}(\lambda)$ are compared with the in-situ $R_{r s}(\lambda)$ spectra for three water provinces (e.g., relatively clear, highly turbid, and moderately turbid waters) (Figure 6). It should be noted that simulated $R_{r s}(\lambda)$ are found in good agreement with the measured $R_{r s}(\lambda)$ curves from relatively clear and turbid waters. The agreement of spectral shape and magnitude are encouraging and show noticeable variability in the visible-near-infra-red domains $(400-720 \mathrm{~nm})$ due to the highly variable in-water constituents of these waters. $S S$ values over $5 \mathrm{~g} \mathrm{~m}^{-3}$ are sufficient to mask the $C h l$, signal, thereby causing large errors in deriving the $R_{r s}(\lambda)$ values with this model. It is evident that when $C h l$, concentrations decrease with increasing or decreasing $S S$ concentrations, the $R_{r s}(\lambda)$ curves become closer to the measured $R_{r s}(\lambda)$ spectra (Figure $6 \mathrm{a}$ and $\mathrm{b}$ ).
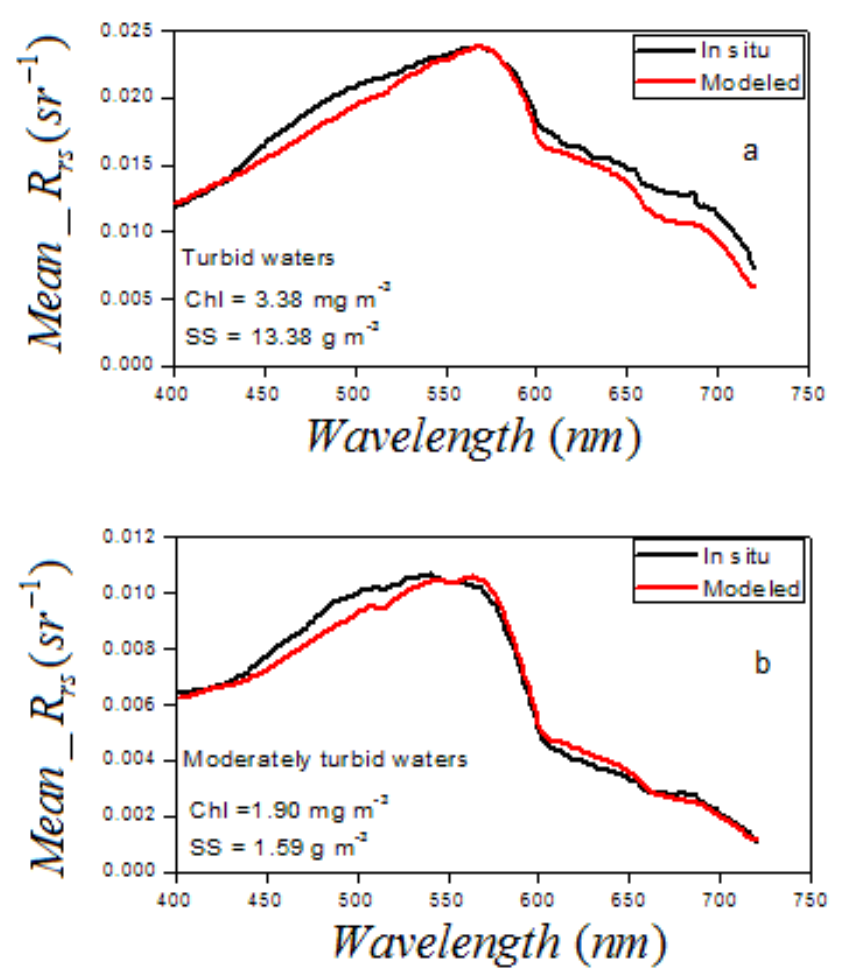

Fig. 6. Comparison of the simulated remote sensing reflectance $\left(R_{r s}\right)$ with in-situ data in coastal waters of the South Sea of Korea.

By contrast, $R_{r s}(\lambda)$ values from highly turbid waters peak toward the red wavelengths because of the high turbidity caused by tidal activities and bottom circulations (Figure 6a). Consequently, elevated SSC increased the backscattering more than the absorption in the longer wavelengths. This drew the attention of the researchers and encouraged them to exploit the usefulness of single band radiance or reflectance at these wavelengths for remote estimation of $S S$ from satellites [53]. In cases of moderately clear waters, $R_{r s}(\lambda)$ values tend to increase in the blue wavelength region and decrease in the longer wavelength region. This suggests profound absorption by water itself with $C h l, 1.9 \mathrm{mg} \mathrm{m}^{-3}$ and SSC $1.59 \mathrm{~g} \mathrm{~m}^{-3}$ (Figure 6b)

\section{Validation of the model results with in-situ data}

To assess the performance of new model, the results are compared with in-situ $R_{r s}(\lambda)$ values. Few statistical measures were used to assess the model performance, namely the root means square error (RMSE), mean relative error (MRE), bias, slope, and correlation coefficient $\left(R^{2}\right)$ [54]. Figure 7 shows the comparison of simulated $R_{r s}(\lambda)$ values with the in-situ $R_{r s}(\lambda)$ values at $400,412,440,490,510,550,670,685 \mathrm{~nm}$. Table I presents the statistical results for the present model. 

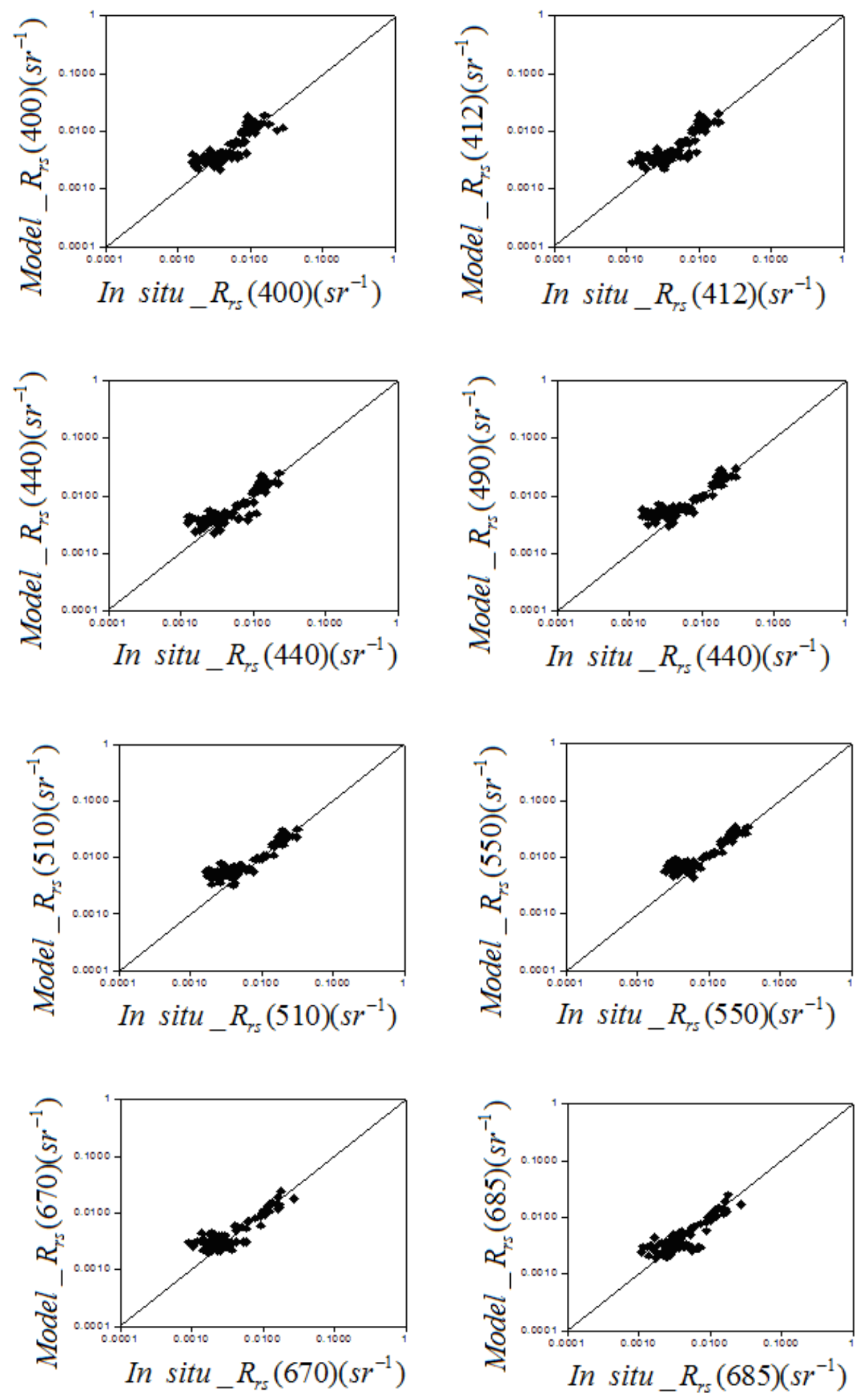

Fig. 7. Scatterplots of the simulated remote sensing reflectance $\left(R_{r s}\right)$ versus in-situ $R_{r s}$ data for relatively cleared, turbid and relatively clear waters in the South Sea of Korea $(\mathrm{N}=83)$. 
TABLE I. STATISTICAL COMPARISON BETWEEN THE SIMULATED AND IN SITU DATA OF REMOTE SENSING REFLECTANCE. RMSE AND MRE AND LINEARREGRESSION RESULTS OF THE MEASURED DATA AT 400, 412, 440, 490, 510, 550, 670, AND $685 \mathrm{~nm}$.

\begin{tabular}{c|cccccc}
\hline AOPs & MRE & RMSE & SLOPE & $\mathbf{R}^{2}$ & BIAS & N \\
\hline $\mathrm{R}_{\mathrm{rs}}(400)$ & -0.0103 & 0.1537 & 0.9447 & 0.724 & -0.0236 & 83 \\
$\mathrm{R}_{\mathrm{rs}}(412)$ & -0.02 & 0.1715 & 1.0188 & 0.7308 & -0.0459 & 83 \\
$\mathrm{R}_{\mathrm{rs}}(440)$ & -0.0336 & 0.2104 & 1.1597 & 0.7496 & -0.0765 & 83 \\
$\mathrm{R}_{\mathrm{rs}}(490)$ & -0.0499 & 0.2457 & 1.3093 & 0.7682 & -0.1096 & 83 \\
$\mathrm{R}_{\mathrm{rs}}(510)$ & -0.0542 & 0.2369 & 1.2973 & 0.7874 & -0.1175 & 83 \\
$\mathrm{R}_{\mathrm{rs}}(550)$ & -0.0517 & 0.1995 & 1.1952 & 0.7872 & -0.1075 & 83 \\
$\mathrm{R}_{\mathrm{rs}}(670)$ & -0.0315 & 0.2325 & 1.1912 & 0.6942 & -0.0769 & 83 \\
$\mathrm{R}_{\mathrm{rs}}(685)$ & -0.0104 & 0.1973 & 1.1002 & 0.6924 & -0.0248 & 83 \\
\hline
\end{tabular}

It is apparent that comparison of the simulated $R_{r s}(\lambda)$ values with in-situ data indicates good agreement over the entire range of data at all wavelengths, which suggests that the new model works very well in all three water provinces. Hence, errors associated with the new model decreased and slopes and $R^{2}$ values increased at all wavelengths (MRE -0.054 -0.01; RMSE $0.15 \sim 0.24$, bias $-0.11 \sim-0.023$, slope $0.94 \sim 1.3, \mathrm{R}^{2} 0.69 \sim 0.787$ ). A slight overestimation of $R_{r s}(\lambda)$ values with the new model is still noticed at the lower end of the scatter plots, which suggests that there is profound effect of suspended sediment particles in seawater IOPS and hence in the AOPS.

\section{Implications for the optical remote sensing}

The remote sensing reflectance is an essential parameter among the $A O P s$, which is normally used as a proxy for the derivations of all the IOPS. Usefulness of remote sensing reflectance in coastal/oceanic waters is highlighted by many researchers on regional and global scales. Most of the recent reflectance modeling approaches are based on the three distinct methods: Analytical, semi-analytical and empirical. In these approaches parameterizations mainly depend on radiance. However, a semi-analytical approach has been developed as a function of $C h l$ and $S S$, which is totally independent on the radiance $(A O P s)$. The new model provides encouraging results in coastal waters. The values of remote sensing reflectance can be effective for modeling the IOPS and to solve inversion problems in ocean optics. This model also has the potential to describe the variability of reflectance spectra in turbid and relatively clear waters. Further, this variability shows the considerable scenario to understand and inspect the fluorescence phenomenon towards the red and near-infrared wavelength regions.

\section{CONCLUSION}

In this study, a new reflectance model has been developed to simulate $R_{r s}$ and validate with in-situ data. For modeling, the optical properties of pure water were taken from [34, 47]. The values of specific backscattering by suspended sediments were taken from [48]. The present model for predicting the values of $R_{r s}(\lambda)$ relies upon descriptions relating to the inherent optical properties of absorption and backscattering through the ratio of $f / Q$. The model uses $C h l, S S$ and $C D O M$ contents as inputs to estimate the required IOPS ( $a_{s s}, a_{g}$, and $a_{p h}$ ). Further, the $Q$ and $f$ factors that are variable and depend in a complicated manner upon the solar zenith angle, the geometric structure of the radiance field, and on the seawater IOPs are estimated by their respective equations and used in the present model. As a result, the new model produces $R_{r s}(\lambda)$ curves closely matching with the insitu measurements data. The shape and magnitude of the $R_{r s}(\lambda)$ curves are also closely comparable with measured $R_{r s}(\lambda)$ data. These results suggest that our reflectance model has several potential uses, including the examination of regional variability in the $R_{r s}(\lambda)$ versus $C h l$ and other inwater constituents relationships. The present model would be helpful to study and understand the relative contribution of each constituent to the bio-optics of coastal waters of Korea and serve as a guide for the improvement of novel models for the estimation of IOPS in these waters.

It is expected that further developments in oceanographic and ocean optics instrumentation would provide better understandings of marine environment in these waters. Thus, the future work will be on the Raman scattering, bottom reflectance and fluorescence, and to refine our model based on understanding of the influences of the IOPS an in-water properties on the remote sensing reflectance property.

\section{ACKNOWLEDGEMENTS}

This work received support from the Korea Ocean Research and Development Institute (KORDI), Seoul 425-600, Korea (Contract number OEC/10-11/101/KORD/ PSHA). This work was also supported by INCOIS under the grant (OEC/1011/102/INCO/PSHA) of the SATCORE program.

\section{REFERENCES}

[1] H. R. Gordon, O. B. Brown, M. M. Jacobs, "Computed relationships between the inherent and apparent optical properties of a flat homogeneous ocean", Applied Optics, Vol. 14, No. 2, pp. 417-427, 1975

[2] A. Morel, L. Prieur, "Analysis of variations in ocean color", Limnology and Oceanography, Vol. 22, No. 4, pp. 709-722, 1977

[3] D. Stramski, E. Boss, D. Bogucki, K. J. Voss, "The role of seawater constituents in light backscattering in the ocean", Progress in Oceanography, Vol. 61, No. 1, pp. 27-56, 2004

[4] P. Shanmugam, "A new bio-optical algorithm for the remote sensing of algal blooms in complex ocean waters", Journal of Geophysical Research, Vol. 116, C04016, 2011, doi:10.1029/2010JC006796.

[5] H. R. Gordon, A. Y. Morel, Remote assessment of ocean color for interpretation of satellite visible imagery: A review, Springer-Verlag, New York (USA), 1983

[6] Z. P. Lee, K. L. Carder, S. K. Hawes, R. G. Steward, T. G. Peacock, C. O. Davis, "Model for interpretation of hyperspectral remote sensing reflectance", Applied Optics, Vol. 33, No. 4, pp. 5721-5732, 1994

[7] C. S. Roesler, M. J. Perry, "In situ phytoplankton absorption, fluorescence emission, and particulate backscattering spectra determined from reflectance", Journal of Geophysical Research, Vol. 100, No. C7, pp. 13279-13294, 1995

[8] S. A. Garver, D. A. Siegel, "Inherent optical property inversion of ocean color spectra and its biogeochemical interpretation 1. time series from 
the Sargasso Sea”, Journal of Geophysical Research, Vol. 102, No. C8, pp.18607-18625, 1997

[9] M. Chami, D. Robilliard, "Inversion of oceanic constituents in case I and II waters with genetic programming algorithms", Applied Optics, Vol. 41, No. 30, pp. 6260-6275, 2002

[10] S. Maritorena, D. A. Siegel, A. R. Peterson, "Optimization of a semianalytical ocean color model for global-scale applications", Applied Optics, Vol. 41, No. 15, pp. 2705-2714, 2002

[11] R. M. Chomko, H. R. Gordon, S. Maritorena, D. A. Siegel, "Simultaneous determination of oceanic and atmospheric parameters for ocean color imagery by spectral optimization: a validation", Remote Sensing of the Environment, Vol. 84, No. 2, pp. 208-220, 2003

[12] S. P. Tiwari, P. Shanmugam, "A semi-analytical reflectance model for oceanic waters", Proceedings of the XXXVI OSI Symposium on Frontiers in Optics and Photonics, New Delhi, India, 2011

[13] P. Shanmugam, V. B. Sundarabalan, Y. H. Ahn, J. H. Ryu, “A new inversion model to retrieve the particulate backscattering in coastal/ocean waters", IEEE Geoscience and Remote Sensing, Vol. 49 No. 6, pp. 2463-2475, 2011

[14] J. T. O. Kirk, "Dependence of relationship between inherent and apparent optical properties of water on solar altitude", Limnology and Oceanography, Vol. 29, pp. 350-356, 1984

[15] C. L. Gallegos, D. L. Correl, J. W. Pierce, "Modeling spectral diffuse attenuation, absorption, and scattering coefficients in a turbid estuary", Limnology and Oceanography, Vol. 35, No. 7, pp. 1486-1502, 1990

[16] H. R. Gordon, "Dependence of the diffuse reflectance of natural waters on the sun angle", Limnology and Oceanography, Vol. 34, No. 8, pp. 1484-1489, 1989

[17] A. Morel, B. Gentili, "Diffuse reflectance of oceanic waters: its dependence on Sun angle as influenced by the molecular scattering contribution", Applied Optics, Vol. 30, No. 30, pp. 4427-4438, 1991

[18] Y. J. Park, K. Ruddick, "Model of remote-sensing reflectance including bidirectional effects for case 1 and case 2 waters", Applied Optics, Vol. 44, No. 7, pp. 1236-1249, 2005

[19] M. Tzortziou, A. Subramaniam , J. R. Herman, C. L. Gallegos, P. J. Neale, L. W. Harding Jr., "Remote sensing reflectance and inherent optical properties in the mid Chesapeake Bay", Estuarine, Coastal and Shelf Science, Vol. 72, pp.16-32, 2007

[20] M. X. He, Z. S. Liu, K. P. Du, L. P. Li, R.Chen, K. L. Carder, Z. P. Lee, "Retrieval of chlorophyll from remote-sensing reflectance in the China Seas", Applied Optics, Vol. 39, No. 15, pp. 2467-2474, 2000

[21] A. Morel, H. R. Gordon, "Report of the working group on water color", Boundary Layer Meteorology, Vol. 18, pp. 343-355, 1980

[22] S. C. Johannessen, W. L. Miller, J. J. Cullen, "Calculation of UV attenuation and colored dissolved organic matter absorption spectra from measurements of ocean color", Journal of Geophysical Research, Vol. 108, No. C9, pp. 3301-3314, 2003

[23] M. A. Montes-Hugo, K. L. Carder, R. J. Foy, J. Cannizzaro, E. Brown, S. Pegau, "Estimating phytoplankton biomass in coastal waters of Alaska using airborne remote sensing", Remote Sensing of Environment, Vol. 98, No. 4, pp. 481-493, 2005

[24] R. W. Preisendorfer, "Application of radiative transfer theory to light measurements in the sea", IUGG Monograph, 10, pp. 11-29, 1961

[25] R. W. Austin, Inherent spectral radiance signatures of the ocean surface: Ocean Color Analysis, La Jolla, CA: Scripps Institute of Oceanography, 1974

[26] A. Morel, B. Gentili, "Diffuse reflectance of oceanic waters. 2. Bidirectional aspects", Applied Optics, Vol. 32, pp. 6864-6872, 1993

[27] A. Morel, D. Antoine, B. Gentili, "Bidirectional reflectance of oceanic waters: Accounting for Raman emission and varying particle phase function", Applied Optics; Vol. 41, pp. 6289-6306, 2002

[28] A. Morel, B. Gentili, "Diffuse reflectance of oceanic waters. 3. Implication of bidirectionality for the remote-sensing problem", Applied Optics, Vol. 35, pp. 4850-4862, 1996

[29] H. R. Gordon, O. Brown, R. H. B Evans, J. W. Brown, R. C. Smith, K. S. Baker, D. K. Clark, "A semi-analytic model of ocean color", Journal of Geophysical Research, Vol. 9, pp. 10909-10924, 1988
[30] J. T. O. Kirk, Light and Photosynthesis in Aquatic Ecosystems (2nd ed.), Cambridge: University Press, 1994

[31] J. Krijgsman, Optical remote sensing of water water quality parameters: Interpretation of refletance spectra, Ph.D-Thesis, Delf University, Netherlands (ISBN: 90-6275-952-1), 1994

[32] H. J. Hoogenboom, A. G. Dekker, J. F. De Haan, "Retrieval of chlorophyll and suspended matter in inland waters from CASI data by matrix inversion", Canadian Journal of Remote Sensing, Vol. 24, pp. 144-152, 1998

[33] A. Albert, C. Mobley, "An analytical model for subsurface irradiance and remote sensing reflectance in deep and shallow case-2 waters", Optics Express, Vol. 11, No. 22, pp. 2873-2890, 2003

[34] R. M. Pope, E. S. Fry, “Absorption spectrum (380-700 nm) of pure water. II. Integrating cavity measurements", Applied Optics, Vol. 36, No. 33, pp. 8710-8723, 1997

[35] A. Morel, "Optical Properties of pure water and pure seawater", In Jerlov NG and Steemann- Nielsen E, editors. Optical Aspects of Oceanography. San Diego, CA: Acedemic Press, pp. 1-24, 1974

[36] L. Prieur, S. Sathyendranath, "An optical classification of coastal and oceanic waters based on the specific spectral absorption curves of phytoplankton pigments, dissolved organic matter, and other particulate materials", Limnology and Oceanography, Vol. 26, pp. 671-689, 1981

[37] M. Babin, J. Therriault, L. CLegendre, A. Condal, "Variations in the specific absorption coefficient for natural phytoplankton assemblages: Impact on estimates of primary production", Limnology and Oceanography, Vol. 38, pp. 154-177, 1993

[38] A. Bricaud, A. Morel, M. Babin, K. Allali, H. Claustre, "Variations of light absorption by suspended particles with chlorophyll a concentration in oceanic (Case 1) waters: Analysis and implications for bio-optical models", Journal of Geophysical Research, Vol. 103, No. C13, pp. 31033-31044, 1998

[39] Z. P. Lee, Visible-infrared remote-sensing model and applications for ocean waters, Ph.D-Thesis, University of South Florida, St. Petersburg, Fla, 1994

[40] Z. P. Lee,K. L. Carder, C. D. Mobley, R. G. Steward, J. S. Patch, "Hyperspectral remote sensing for shallow waters. I. A semianalytical model", Applied Optics, Vol. 37, No. 27, pp. 6329-6338, 1998

[41] K. L. Carder, S. K. Hawes, K. A. Baker, R. C. Smith, R. G. Steward, B. G. Mitchell, "Reflectance model for quantifying chlorophyll a in the presence of productivity degradation products", Journal of Geophysical Research, Vol. 96, No. C11, pp. 20599-20611, 1991

[42] E. R. D’Sa, G. Steward, A. Vodacek, N. V. Blough, D. Phinney, "Optical absorption of seawater colored dissolved organic matter determined using a liquid capillary waveguide", Limnology and Oceanography, Vol. 44, pp. 1142-1148, 1999

[43] P. J. Werdell, S. W. Bailey, “An improved in-situ bio-optical data set for ocean color algorithm development and satellite data product validation", Remote Sensing of Environment, Vol. 98, No. 1, pp. 122140,2005

[44] A. Morel, "Optical modeling of the upper ocean in relation to its biogenous matter content (case 1 water)", Journal of Geophysical Research, Vol. 93, No. 10, pp. 10749-10768, 1988

[45] H. R. Gordon, "Dependence of the diffuse reflectance of natural waters on the sun angle", Limnology and Oceanography, Vol. 34, No. 8, pp. 1484-1489, 1989

[46] H. Loisel, A. Morel, "Light scattering and chlorophyll concentration in case 1 waters: A reexamination", Limnology and Oceanography, Vol. 43, pp. 847-858, 1998

[47] R. C. Smith, K. S. Baker, "Optical properties of the clearest natural waters (200-800 nm)", Applied Optics, Vol. 20, No. 2, pp.177-184, 1981

[48] Y. H. Ahn, Optical properties of biogenous and mineral particles present in the ocean. Application: inversion of reflectance, $\mathrm{PhD}$ Thesis, Paris-VI University, 1990

[49] Y. H. Ahn, P. Shanmugam, "Detecting the red tide algal blooms from satellite ocean color observations in optically-complex Northeast-Asia Coastal waters", Remote Sensing of Environment, Vol. 103, No. 4, pp. 419-437, 2006 
[50] Y. H. Ahn, P. Shanmugam, "Derivation and analysis of the fluorescence algorithms to estimate chlorophyll a concentrations in ocean waters", Journal of Optics: A, Pure and Appllied Optics, Vol. 9, pp. 352-362, 2007

[51] P. Shanmugam, "An evaluation of inversion models to retrieve IOPs in Korean waters", Journal of Oceanography, Vol. 66, pp. 815-830, 2010

[52] A. Morel, A. Bricaud, "Theoretical results concerning light absoprtion in a discrete medium, and application to specific absoprtion of phytoplankotn”, Deep-Sea Research, Vol. 28, pp. 1375-1393, 1981

[53] Y. H. Ahn, J. E. Moon, S. Gallegos, "Development of suspended particulate matter algorithms for ocean color remote sensing", Korean Journal of Remote Sensing Vol. 17, No. 4, pp. 285-295, 2001

[54] Z. P. Lee, International Ocean-Colour Coordinating Group (IOCCG), Remote sensing of inherent optical properties: Fundamentals, tests of algorithms and applications, in Reports of the International Ocean-Color Coordinating Group, edited by Rep. 5, Dartmouth, N.S., Canada, 2006

\section{AUTHORS PROFILE}

Surya Prakash Tiwari received the B. Sc. degree in Mathematics \& Physics, M. Sc. in Physics with Electronics specialization degree from Gorakhpur University, Uttar Pradesh, India, in 2005 and in 2007 respectively and M. Tech. in remote sensing and GIS from SRM University, Chennai, India in 2009. He is currently working toward the Ph.D. degree in the Department of Ocean Engineering, Indian Institute of Technology (IIT) Madras, Chennai, India. His research interests are focused on ocean colour remote sensing, optical properties of oceanic and coastal waters and bio-optical modeling.

Palanisamy Shanmugam received the Ph.D. degree in optical remote sensing from Anna University, Chennai, India, in 2002. He is currently an Associate
Professor with the Indian Institute of Technology (IIT) Madras, Chennai, India. He has undertaken a broad range of research in ocean optics and ocean color remote sensing at the Korea Ocean Research and Development Institute (KORDI), Seoul, Korea during 2003-2008. His research is focused on the development of atmospheric and in-water algorithms for ocean color remote sensing and the characterization of underwater light field in the coastal ocean. He has been a Principle Investigator of several projects funded by the Indian government and KORDI.

Yu-Hwan Ahn received the Ph.D. degree in optical oceanography from Paris University, Paris, France, in 1990. He was the Head of the Ocean Color Remote Sensing Laboratory at the National Fisheries Research and Development Institute (NFRDI) between 1993 and 1997. He was then the Director of Ocean Satellite Remote Sensing and Observation Technology Research Department, Korea Ocean Research and Development Institute (KORDI), Seoul, Korea and he was also Leader of Korea Ocean Satellite Center (KOSC) in KORDI. He has been responsible for the Korean geostationary ocean color satellite (GOCI) program. He is currently Research Emeritus in KORDI. His research interests are in the field of optical oceanography, including optical properties of oceanic particles, under water light field and development of ocean color remote sensing techniques.

Joo-Hyung Ryu received the Ph.D. degree in Geology and Earth System Sciences from Yonsei University, Seoul, Korea, in 2001. He is currently the leader of Korea Ocean Satellite Center in KORDI, Korea. He is currently the PI of the GOCI scientific ocean application project. His research is focused on the development of ocean color remote sensing techniques and understanding the coastal zone processes. 